\title{
T2-prepared steady-state free-precession for detection of hemodynamic significance of coronary artery stenosis - a comparison to fractional flow reserve
}

Thomas Walcher", Robert Manzke, Vinzenz Hombach, Wolfgang Rottbauer, Jochen Wöhrle, Peter Bernhardt

From 16th Annual SCMR Scientific Sessions

San Francisco, CA, USA. 31 January - 3 February 2013

\section{Background}

BOLD CMR has been shown to be able to detect myocardial perfusion differences. However, validation of BOLD CMR against FFR is lacking. Aim of our study was to analyze the potential diagnostic accuracy of blood oxygen level-dependent (BOLD) cardiac magnetic resonance imaging (CMR) in comparison to invasively measured fractional flow reserve (FFR) which served as gold standard for a hemodynamic significant coronary lesion.
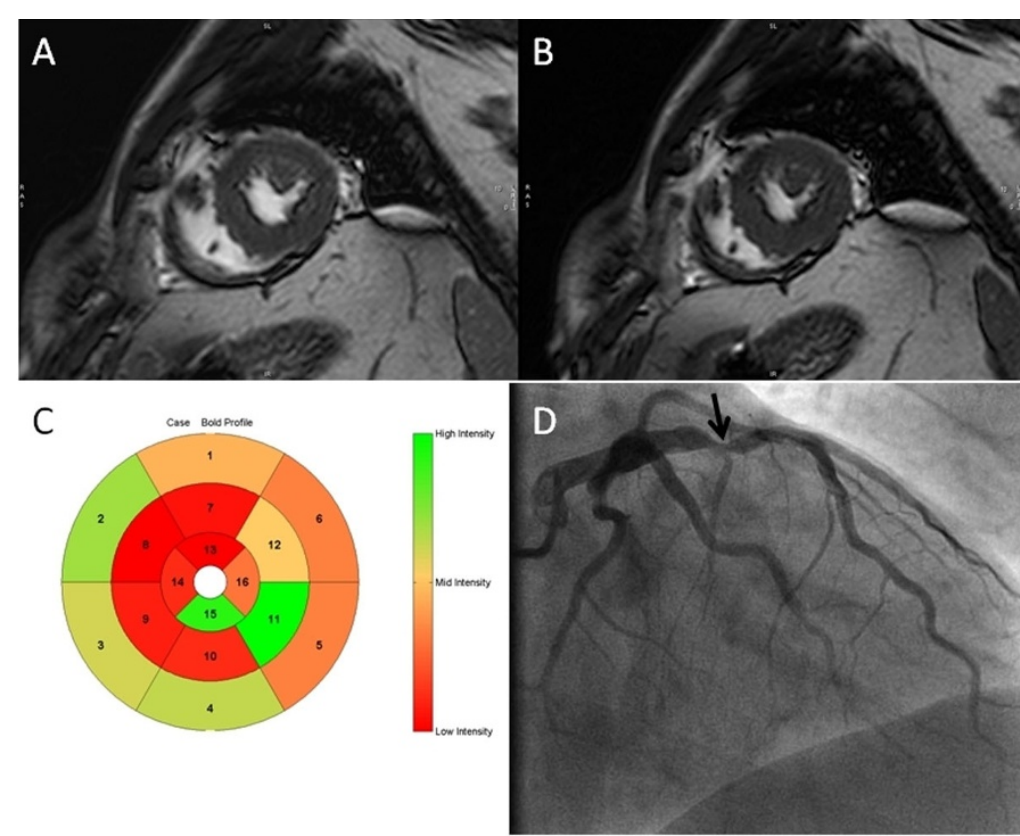

Figure 1 BOLD image examples in a midventricular short axis at rest (A) and during adenosine infusion (B) and color-encoded 16-segments BOLD signal intensity increase $(C)$ in a patient with LAD stenosis (arrow) as seen on coronary angiogram (D).

Department of Internal Medicine II, Cardiology, Ulm, Germany

C 2013 Walcher et al; licensee BioMed Central Ltd. This is an Open Access article distributed under the terms of the Creative Commons 


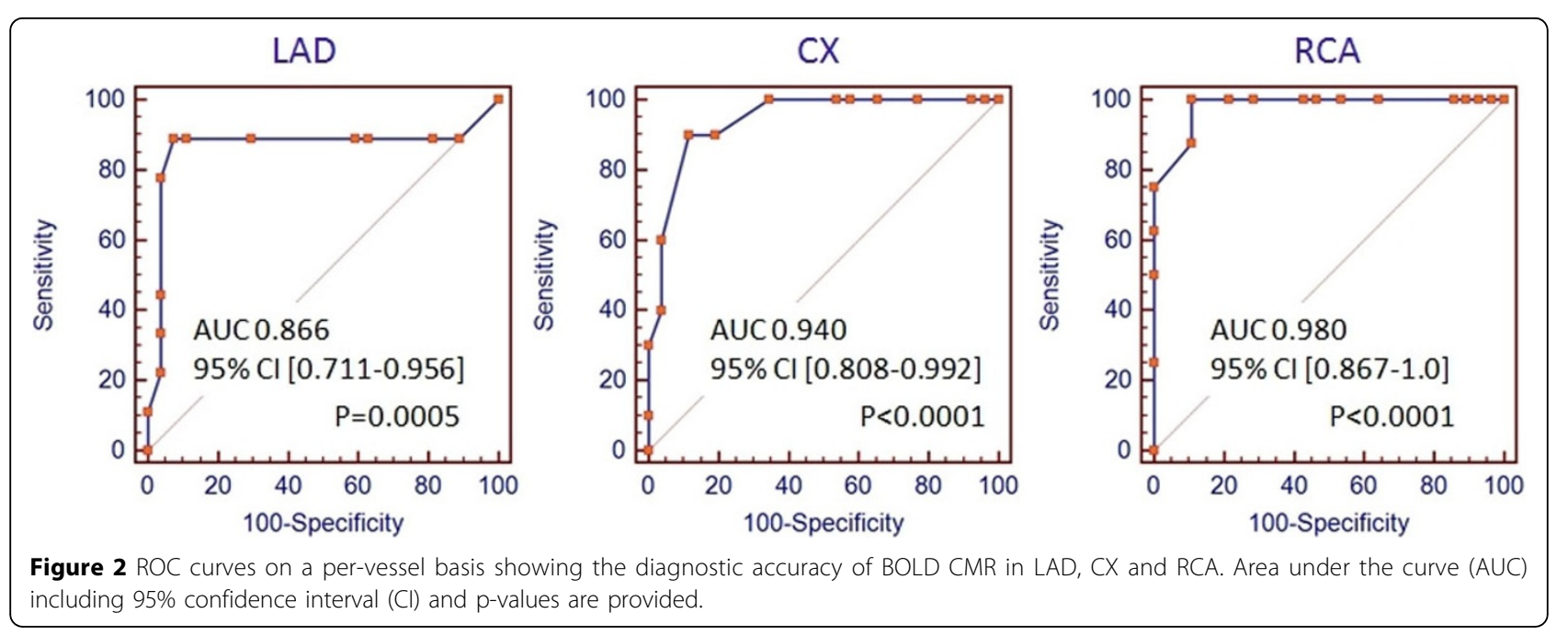

\section{Methods}

BOLD image was performed at rest and during adenosine infusion in a $1.5 \mathrm{~T}$ CMR scanner. Thirty-six patients were analyzed for relative BOLD signal intensity increase according to the 16-segment model. Invasive FFR measurements were performed in the major three coronary arteries during adenosine infusion in all patients. A FFR $\leq 0.8$ was regarded to indicate a significant coronary lesion.

\section{Results}

Relative BOLD signal intensity increase was significantly lower in myocardial segments supplied by coronary arteries with a FFR $\leq 0.8$ compared to segments with a FFR $>0.8(1.1 \pm 0.2$ vs. $1.5 \pm 0.2, \mathrm{p}<0.0001)$. Sensitivity and specificity yielded $88.2 \%$ and $89.5 \%$, respectively.

\section{Conclusions}

CMR BOLD imaging reliably detects hemodynamic significant CAD and is thus an alternative to contrastenhanced perfusion studies.

\section{Funding}

This study was partly supported by a grant of the University of Ulm (L.SBN.0050).

Published: 30 January 2013

Submit your next manuscript to BioMed Central and take full advantage of:

- Convenient online submission

- Thorough peer review

- No space constraints or color figure charges

- Immediate publication on acceptance

- Inclusion in PubMed, CAS, Scopus and Google Scholar

- Research which is freely available for redistribution 